\title{
Risk factors for amputation in extremity vascular injuries in Saudi Arabia
}

\author{
This article was published in the following Dove Press journal: \\ Vascular Health and Risk Management \\ 24 May 2016 \\ Number of times this article has been viewed
}

\author{
Abdullah Al Wahbi \\ Salman Aldakhil \\ Saud Al Turki \\ Abdulrahman El Kayali \\ Hussein Al Kohlani \\ Abdulaziz Al Showmer \\ Department of Surgery, Division of \\ Vascular Surgery, King Abdulaziz \\ Medical City, Riyadh, Saudi Arabia
}

\begin{abstract}
Amputation is most closely associated with blunt, lower limb injuries associated with vascular trauma. These vascular injuries require a special attention to prevent life and limb loss. Patient outcomes can also be improved by organizing vascular trauma data into appropriate systems to facilitate future studies.
\end{abstract}

Keywords: vascular injuries, extremities trauma, amputation, ischemia

\section{Introduction}

Trauma from road traffic accidents (RTAs) is a leading public health problem, worldwide. The incidence of vascular injuries has increased worldwide during the past few years and RTAs are now the most common human accident. ${ }^{1}$ The rise of RTAs is the result of rapidly growing urban developments, and increase in the number of roads. Saudi Arabia has the highest RTA-toll in the world, according to a report from the World Health Organization. From 2008 to 2009, the total number of RTA deaths was 645,813 , and around one-third of all hospital beds is occupied by RTA victims, with the most common RTA-injury being limb loss. In addition, 13 of every 1,000 accidents result in a fatality. ${ }^{2-5}$

The frequency of extremity-localized vascular injuries is difficult to quantify. Worldwide reports of vascular injuries of the extremities often include other causes of trauma such as penetrating injuries, falls, and explosions. At a high-volume urban trauma center in Houston, TX, USA, Feliciano et $\mathrm{al}^{6}$ reported $\sim 55$ lower-extremity vascular injuries/year. Magee et $\mathrm{al}^{7}$ reported 4.7 injuries/year in the UK and, in Australia, Tobin et $\mathrm{al}^{8}$ reported 10 injuries/year. ${ }^{6-8}$

There have been few reports about vascular injuries from RTA in our region. Jawas et $\mathrm{al}^{9}$ reported that 1.87 patients/10,0000 patients were hospitalized because of vascular injuries from RTAs in Al-Ain city, United Arab Emirates and upper limb vascular injuries were the most common. ${ }^{9}$ Al-Salman et $\mathrm{al}^{10}$ stated that $91 \%$ of vascular injuries associated with limb fractures were caused by RTA; and Wali ${ }^{11}$ reported that $33 \%$ of upper limb vascular trauma in Asir region, Saudi Arabia, was caused by RTAs. ${ }^{10,11}$

There have been no reports of limb loss as a result of these vascular injuries. This may be because RTAs most commonly affect younger individuals. RTAs are associated with devastating socioeconomic and psychological impacts on the affected victim and his/her family and community, especially if the RTA results in limb loss. Depression and anxiety are the most common psychological effects of RTAs amputee population. ${ }^{11}$
Correspondence: Abdullah AI Wahb Department of Surgery,

Division of Vascular Surgery,

King Abdulaziz Medical City,

PO Box 22490, Riyadh I I426, Saudi Arabia

Tel +966 II 80 I I I I I Ext I5442

Email amw8855@gmail.com 
Limb loss as the effect of extremity vascular trauma are classified by the mode, site, and clinical findings of the injury. ${ }^{12}$ Blunt injuries during RTAs are most commonly associated with limb loss; and penetrating injuries yield the highest mortality rates. ${ }^{13,14}$ In lower limb trauma, although the superficial femoral artery is the most commonly injured, the popliteal artery, especially when associated with nerve damage, is the most commonly associated with limb loss. ${ }^{12-14}$ There is a lack of comprehensive data on extremity-specific vascular injuries and the outcomes of patients with these injuries in Saudi Arabia and the Middle East. Upper limb amputation resulting from vascular injuries is also sparsely studied.

Our goal is to identify the risk factors associated with limb loss in vascular injuries, at King Abdulaziz Medical City (KAMC), Riyadh, Saudi Arabia. We will try to identify the most common site and mode of vascular injuries associated with limb loss, and evaluate associated injuries' effect on patient's outcome.

\section{Methodology}

Our study was conducted at the Emergency Department (ED) at KAMC in Riyadh, Saudi Arabia; this is categorized as a high-flow, level III trauma center. This department is also recognized as the fourth-best ED outside USA. The ED at KAMC houses an admission area, triage area, critical care, adult care, pediatric care, and urgent care, and ED observation area. The maximum capacity of the ED is 500 patients. All extremitylocalized vascular injuries treated between January 1992 and December 2011 at KAMC were included in our study. Both sexes, all age groups, and outcomes, without time limits, were considered. Limbs with irreversible ischemia were excluded.

This study was conducted as an analytical cross-sectional study (ie, we tested our hypothesis and examined our results to reveal the prevalence of RTA-caused extremity-specific vascular injuries among included patients at the time of our study). We also employed a well-defined inclusion criteria, sampling methods, and data-collection methods.

To reveal the risk factors associated with extremity-loss after vascular injuries, we used the online sample calculator from (Raosoft Inc., Seattle, WA, USA). That has a margin of error of $10 \%$, a confidence level of $95 \%$, and an expected prevalence of $50 \%$. As the population size is unknown, we used an estimation of 20,000 patients, (As we used 20,000 patient population the sample size should be 96 , however we studied 32 patients only due to study limitations mentioned at the end of the paper).

We used a nonprobability convenience to select the sample between January 1992 and December 2011 at
KAMC. We also included a self-developed data-collection form, created using data from literature reviews, and reviewed by vascular surgery experts. The data were collected from charts by our co-investigator, and were analyzed using SPSS and EXCEL programs (IBM Software, New York , NY, USA).

The data-collection form contains quantitative data (eg, age), and qualitative data (eg, sex, mode of injury, vessel(s) injured, clinical findings, associated injuries, type of injury on exploration, type of procedure performed, and the outcome of the procedure). The procedures' outcomes were compared among all other qualitative data.

Statistical analysis of collected data was performed using SPSS. Descriptive statistics include percentages and frequencies. To calculate inferential statistical data, we used Fisher's exact test to compare limb-lost and limb-salvaged patients. A $P$-value of $<0.05$ is considered statistically significant in this study.

The approval for this study was submitted to King Abdullah International Research Centre; and once we received the approval, data collection was started. We ensured patient confidentiality by using a coding system to identify patients during data entry. The data were also saved in protected computers and on hard disks, where only the principle investigator and co-investigators could access. As a policy of King Abdulaziz Medical City, all patients (or their relatives) sign an informed consent that their file information may be used for research without their name or identity.

\section{Results}

Selecting patients who met our inclusion criteria yielded 32 patients, however, because of missing data, only few files were complete. The most common missing data were clinical findings (23 missing data), type of injury observed upon exploration (14 missing data), and associated injuries (ten missing data).

Amputations represented $46 \%$ of patient outcomes in our study. The most common mode of injury was blunt injury, with 22 injuries (ie, 71\% of all RTA-caused extremity injuries). The other modes of injury we observed were stab and shotgun injuries (29\%).

The most common vessels injured were the profunda brachii arteries (five injuries) in the upper limb and dorsalis pedis arteries (five injuries) in the lower limb; constituting $19 \%$ of the total RTA-caused vascular limb injuries. The least common vessels affected were the superficial femoral arteries (one injury) and the axillary arteries (one injury). The 
most common type of vessel injury was complete transection and interposition vein graft was the most common type of repair. Also, simple nerve injury was the most common clinical findings.

The highest amputation rate was caused by blunt trauma mode and damage to the superficial femoral artery and the above-knee popliteal artery (100\% amputation rate; Tables 1 and 2). None of the upper limb injuries caused amputation.

The presence of compound fractures, associated with limb arterial injury yielded the highest incidence of limb loss in the "associated injuries" category, with a $100 \%$ amputation rate. The most common associated injury was a simple fracture (eleven injuries). The least frequent incidence of amputation was in case of associated nerve injuries (Table 3).

Table I Mode of injury and association with amputation

\begin{tabular}{lll}
\hline Mode Of Injury & Amputation & \\
\cline { 2 - 3 } & No & Yes \\
\hline Blunt & $1045 \%$ & $1255 \%$ \\
Stab & $7100 \%$ & $00.0 \%$ \\
Shotgun & $2100.0 \%$ & $00.0 \%$ \\
\hline
\end{tabular}

Table 2 Vessel injured and association with amputation

\begin{tabular}{lll}
\hline Vessel Injured & \multicolumn{2}{l}{ Amputation } \\
\cline { 2 - 3 } & Yes & No \\
\hline Common femoral artery & I $50 \%$ & I $50 \%$ \\
Deep femoral artery & $2100 \%$ & $00.0 \%$ \\
Superficial femoral artery & $00.0 \%$ & $\mathrm{I} 100.0 \%$ \\
Above knee popliteal artery & $00.0 \%$ & $3100 \%$ \\
Below knee popliteal artery & $250 \%$ & $250 \%$ \\
Combined above below popliteal artery & $00.0 \%$ & $1 \quad 100 \%$ \\
Axillary artery & $1100 \%$ & $00.0 \%$ \\
Profunda brachii artery & $5100.0 \%$ & $00.0 \%$ \\
Ulnar artery & $2100 \%$ & $00.0 \%$ \\
Dorsalis pedis artery & $5100 \%$ & $00.0 \%$ \\
\hline
\end{tabular}

Table 3 Statistical significance of injury mode, limb injured, and associated injuries with amputation

\begin{tabular}{llll}
\hline Mode of injury & \multicolumn{2}{l}{ Amputation } & P-value \\
\cline { 2 - 3 } & Yes & No & \\
\hline Blunt & 12 & 10 & 0.02 \\
Other & 1 & 9 & \\
Limb injured & & 8 & 0.02 \\
Upper limb & 0 & 10 & \\
Lower limb & 8 & & \\
Associated injuries & & 8 & 0.03 \\
Compound fractures & 7 & 7 & \\
Nerve injury & 0 &
\end{tabular}

\section{Discussion}

The incidence of extremity vascular injuries has increased during the last decade. These injuries are caused by a wide spectrum of mechanisms. The most common mode of injury in civilian practice that we observed was blunt injuries, but the incidence of penetrating injuries is also increasing.

Vascular injuries were most commonly associated with blunt-force trauma $71 \%(\mathrm{n}=22)$. Also, amputation was highly associated with blunt-force injuries as $92 \%$ of blunt-force affected limbs resulting from RTAs were amputated $(\mathrm{n}=12$, $P=0.02)$. In Saudi Arabia and Gulf countries, there are few studies that examine the association between vascular injuries and amputation rates. In a local study in Riyadh, Saudi Arabia, Al-Salman et $\mathrm{al}^{10}$ reported that $57 \%$ of vascular injuries were caused by blunt trauma, and $91 \%$ of these blunttrauma vascular injuries were caused by RTAs. ${ }^{10}$ In contrast to our study, the most common mode of injury in Kuwait between 1992 and 2000 was penetration, representing 43\% of injuries. ${ }^{15}$ This may be an effect of the Gulf war. Hafez et al ${ }^{12}$ reported that penetrating injuries were the most common mode of injury and have a higher amputation risk than other modes of injury. ${ }^{13}$ In Finland and Sweden, Shaban et al ${ }^{17}$ also observed a $34 \%$ incidence of blunt-force injuries. ${ }^{17}$

In our study, lower limb injuries $(\mathrm{n}=8, P=0.02)$ are more likely to result in amputation than upper limb injuries. Similar to our findings, Kauvar et al reported that popliteal artery injuries were associated with $50 \%$ of amputations performed. ${ }^{14}$ Whereas, Topal et a ${ }^{18}$ showed that one of the significant risk factors for amputation is multiple arterial injuries below knee $(P<0.001){ }^{18}$

Vascular injuries are also associated with many other injuries. Fractures and amputation were closely linked among our patient pool and nerve injuries were less commonly associated with amputation $(P=0.03)$. Hafez et $\mathrm{al}^{13}$ found that bone fracture(s) presented with lower limb arterial injury yielded the most frequent limb loss $(24.8 \%) .{ }^{13}$

Our study has many limitations. The sample is small and several needed data were not documented in the charts. Our new computerized patients' files system will help in collecting data in our future studies.

\section{Conclusion}

In this part of the world, amputation risk factors require more investigation, especially studies on large patient populations. A national vascular trauma registry also needs to be created to facilitate the identification of vascular trauma mechanisms and the risk factors for adverse effects (eg, amputation). This will help us to devise prevention strategies for unwanted 
outcomes for patients with vascular injuries of the limbs. We aim to use this study as a proposal for a vascular trauma registry in our hospital.

\section{Disclosure}

The authors report no conflicts of interest in this work.

\section{References}

1. Fingerhut A, Leppäniemi AK, Androulakis GA, et al. The European experience with vascular injuries. Surg Clin North Am. 2002;82:175-188.

2. Ansari S, Akhdar F, Mandoorah M, Moutaery K. Causes and effects of road traffic accidents in Saudi Arabia. Public Health. 2000;1:37-39.

3. Bendak S, Al-Saleh K. Seat belt utilisation and awareness in UAE. Int $J$ Inj Contr Saf Promot. Epub 2012 Nov 19.

4. Naeem Z. Road traffic injuries - changing trend? Int J Health Sci (Qassim). 2010;4:v-viii.

5. Ansari Mohammed ZRH. Trauma in the western region of Saudi Arabia. Emerg Med. 1998;10:31-34.

6. Feliciano DV, Herskowitz K, O'Gorman RB, et al. Management of vascular injuries in the lower extremities. J Trauma. 1988;28:319-328.

7. Magee TR, Collin J, Hands LJ, Gray DW, Roake J. A ten-year audit of surgery for vascular trauma in a British teaching hospital. Eur J Vasc Endovasc Surg. 1996;12:424-427.

8. Tobin SA, Gurry JF, Doyle JC, Connell JL, Vidovich JD. Vascular trauma at a university teaching hospital. Aust N Z J Surg. 1988;58:873-877.
9. Jawas A, Hammad F, Eid HO, Abu-Zidan FM. Vascular injuries following road traffic collisions in a high-income developing country: a prospective cohort study. World J Emerg Surg. 2010;5:5-13.

10. Al-Salman MM, al-Khawashki H, Sindigki A, Rabee H, al-Saif A, al-Salman Fachartz F. Vascular injuries associated with limb fractures. Injury. 1997;28:103-107.

11. Wali MA. Upper limb vascular trauma in the Asir region of Saudi Arabia. Ann Thorac Cardiovasc Surg. 2002;8:298-301.

12. Hawamdeh ZM, Othman YS, Ibrahim AI. Assessment of anxiety and depression after lower limb amputation in Jordanian patients. Neuropsychiatr Dis Treat. 2008;4:627-633.

12. Hafez HM, Woolgar J, Robbs JV. Lower extremity arterial injury: results of 550 cases and review of risk factors associated with limb loss. J Vasc Surg. 2001;6:1212-1219.

14. Kauvar DS, Sarfati MR, Kraiss LW. National trauma databank analysis of mortality and limb loss in isolated lower extremity vascular trauma. J Vasc Surg. 2011;6:1598-1603.

15. Bilgen S, Türkmen N, Eren B, Fedakar R. Peripheral vascular injuryrelated deaths. Ulus Travma Acil Cerrahi Derg. 2009;4:357-361.

16. Asfar S, Al-Ali J, Safar H, et al. 155 vascular injuries: a retrospective study in Kuwait, 1992-2000. Eur J Surg. 2002;168:626-630.

17. Shaban S, Ashour M, Bashir M, El-Ashaal Y, Branicki F, Abu-Zidan FM. The long term effects of early analysis of a trauma registry. World $J$ Emerg Surg. 2009;4:42.

18. Topal AE, Eren MN, Celik Y. Lower extremity arterial injuries over a six-year period: outcomes, risk factors, and management. Vasc Health Risk Manag. 2010;6:1103-1110.
Vascular Health and Risk Management

\section{Publish your work in this journal}

Vascular Health and Risk Management is an international, peerreviewed journal of therapeutics and risk management, focusing on concise rapid reporting of clinical studies on the processes involved in the maintenance of vascular health; the monitoring, prevention and treatment of vascular disease and its sequelae; and the involvement of

\section{Dovepress}

metabolic disorders, particularly diabetes. This journal is indexed on PubMed Central and MedLine. The manuscript management system is completely online and includes a very quick and fair peer-review system, which is all easy to use. Visit http://www.dovepress.com/ testimonials.php to read real quotes from published authors. 